\title{
COMPARATIVE ANALYSIS OF XML AND JSON USING PHP APPLICATION PLATFORM WITH REPRESENTATIONAL STATE TRANSFER ( REST) ARCHITECTURAL
}

\author{
Saryanto, Sumarsono, Nurcahyani Dewi Retnowati \\ Jurusan Teknik Informatika \\ Sekolah Tinggi Teknologi Adisutjipto Yogyakarta \\ informatika@stta.ac.id
}

\begin{abstract}
Data communication in the internet today is so complex as an example of the speed factor becomes very important in communicating, everyone wants fast data communication services provided in order to maximum. In relation to the application as a communication liaison with client server applications, web service using a data serialization format to transmit the data. Before the data is sent, either from the client to the server or vice versa, should be modified in a specific data format beforehand according to the web service is used. Types of data serialization format used in the web service such as XML and JSON. The method used for testing include data serialization method, data measurement method and data parsing method. Data serialization method is used to calculate the time serialization of data from the database to the form of XML and JSON in applications with PHP platform. Data measurement method used to measure the size of the XML and JSON data which based on many fields of data serialization process. Data parsing method is used to calculate the processing time and JSON parsing XML data. Results of comparative analysis of XML and JSON in PHP applications using the architecture Rest can be concluded that the test result of the difference in time and time serialization and JSON parsing XML data is influenced by the number of records, if the number of records the greater the difference in eating time data serialization and parsing the data the greater the time also it can be concluded that the faster the process JSON serialization and parsing XML data is compared. Testing results of the JSON data size is smaller than the size of XML. Data exchange using XML format has a size limit of up to $31456.31 \mathrm{~KB}$ while JSON XML exceeds the size limit. Testing results on the Internet when the number of records up to 50,000 data when the data serialization and parsing time data can not be detected in the database.
\end{abstract}

Keywords: XML, JSON, Webseroice, REST (Representational State Transfer)

\section{Latar Belakang}

Dalam kaitannya sebagai penghubung komunikasi aplikasi client dengan aplikasi server, web service menggunakan suatu format serialisasi data untuk mengirimkan data. Sebelum data dikirimkan, baik dari client menuju server atau sebaliknya, harus diubah dalam format data tertentu dahulu sesuai dengan web service yang digunakan. Jenis format serialisasi data yang digunakan dalam web service diantaranya XML dan JSON.

Salah satu faktor yang mempengaruhi kemampuan format data adalah seberapa cepat request itu diproses, sehingga dibutuhkan request dengan format pertukaran data yang efisien dan cepat dalam proses parsing tersebut. XML merupakan format pertukaran data yang umum digunakan dalam aplikasi dengan berbasis web. Namun hal ini bukanlah cara yang terbaik. XML memiliki sintaks yang komplek dan harus diproses menjadi Document Object 
Model. Format pertukaran data selain XML yaitu JSON yang merupakan bagian dari JavaScript sehingga parsing dilakukan oleh JavaScript tersebut dan memiliki sintaks yang lebih sederhana daripada XML. Secara spesifikasi JSON lebih baik daripada XML.

Penelitian ini dilakukan untuk menganalisis perbandingan waktu serialisasi data, waktu parsing data dan ukuran data XML dan JSON sebagai format pertukaran data dengan arsitektur REST yang diimplementasikan pada aplikasi platform PHP. Selanjutnya dilakukan analisis perbandingan format data antara JSON dan XML serta pembuktian bahwa kemampuan dari format JSON sebagai format pertukaran data lebih baik daripada menggunakan XML.

\section{Landasan Teori}

XML

XML adalah sebuah bahasa markup yang digunakan untuk mengolah meta data (informasi tentang data) yang menggambarkan struktur dan maksud atau tujuan data yang terdapat dalam dokumen XML, namun bukan menggambarkan format tampilan data tersebut. (http://woww.xml.com).

\section{JSON (JavaScript Object Notation)}

JSON adalah format pertukaran data yang ringan, mudah dibaca dan ditulis oleh manusia, serta mudah diterjemahkan dan dibuat oleh komputer. JSON merupakan format teks yang tidak bergantung pada bahasa pemrograman apapun karena menggunakan gaya bahasa yang umum digunakan oleh programmer keluarga $\mathrm{C}$ termasuk $\mathrm{C}, \mathrm{C}++, \mathrm{C \#}$, Java, JavaScript, Perl, Python dll. Oleh karena sifat-sifat tersebut, menjadikan JSON ideal sebagai bahasa pertukaran-data (www.json.org).

\section{Web Service}

Web service dapat diartikan juga sebuah metode pertukaran data, tanpa memperhatikan dimana sebuah database ditanamkan, dibuat dalam bahasa apa sebuah aplikasi yang mengkonsumsi data, dan di platform apa sebuah data itu dikonsumsi.

\section{REST (Representational State Transfer)}

REST menjelaskan bagaimana obyek data dan informasi dipertukarkan dan didistribusikan pada skala besar. Aplikasi REST sebagian besar adalah web itu sendiri, ditandai dengan penggunaan HTTP untuk transportasinya dan URL sebagai mekanisme pengalamatan. REST dapat mendukung semua jenis media, dan XML adalah metode yang paling populer digunakan untuk merepresentasikan informasi terstruktur. REST digunakan bersama dengan HTML, XHTML, RSS dan XML.

\section{Perancangan Infrastruktur Sistem}

Perancangan alur program memberikan gambaran secara visual melalui sebuah gambar untuk dapat memahami bagaimana sistem bekerja dalam proses serialisasi data, proses parsing data dan proses pengukuran data. Perancangan sistem dapat dilihat pada Gambar 1. Perancangan flowchart serialisasi data dan flowchart parsing data dapat dilihat pada Gambar 2 dan Gambar 3. 




Gambar 1 Infrastuktur Sistem

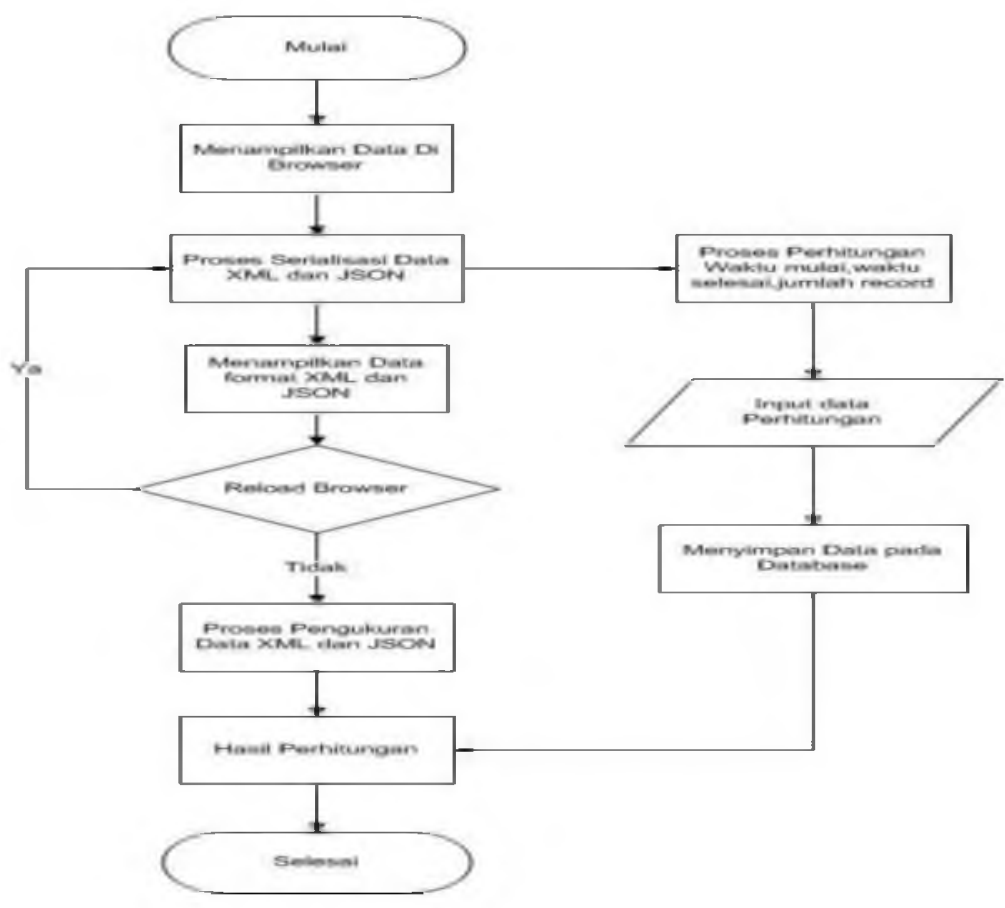

Gambar 2 Perancangan Flowchart Proses Serialisasi Data 




Gambar 3 Perancangan Flowchart Proses Parsing Data

\section{Uji Coba}

\section{Ujicoba Perbandingan Waktu Serialisasi Data}

Dari hasil uji coba proses perhitungan waktu serialisasi data antara XML dan JSON bertujuan membandingkan format data mana yang memiliki waktu paling cepat pada proses serialisasi data. Hasil perbandingan dapat dilihat pada Tabel 1.

Tabel 1. Hasil Ujicoba Waktu Serialisasi Data Di Jaringan Localhost

\begin{tabular}{|c|c|c|c|}
\hline Jumlah_Record & $\begin{array}{c}\text { Waktu Serialisasi } \\
\text { data XML (ms) }\end{array}$ & $\begin{array}{c}\text { Waktu Serialisasi } \\
\text { data JSON (ms) }\end{array}$ & Selisih (ms) \\
\hline 10 & 0.078 & 0.076 & 0.002 \\
\hline 500 & 0.098 & 0.084 & 0.014 \\
\hline 1000 & 0.123 & 0.096 & 0.027 \\
\hline 5000 & 0.382 & 0.21 & 0.172 \\
\hline 10.000 & 0.674 & 0.396 & 0.278 \\
\hline 50.000 & 1.951 & 1.232 & 0.719 \\
\hline 100.000 & 5.429 & 2.824 & 2.605 \\
\hline 145.537 & 10.659 & 5.893 & 4.766 \\
\hline 145.538 & Not Detected & 7.896 & - \\
\hline
\end{tabular}




\section{Ujicoba Perbandingan Ukuran Data}

Dari hasil uji coba proses pengukuran format data XML dan JSON bertujuan untuk membandingkan format data mana yang memiliki ukuran paling kecil antara format data XML dan JSON. Hasil perbandingan dapat dilihat pada Tabel 2.

Tabel 2. Hasil Ujicoba Ukuran Data Di Jaringan Localhost

\begin{tabular}{|c|c|c|c|}
\hline Jumlah_Record & $\begin{array}{c}\text { Ukuran Data XML } \\
(\mathbf{K B})\end{array}$ & $\begin{array}{c}\text { Ukuran Data } \\
\text { JSON (KB) }\end{array}$ & Selisih (KB) \\
\hline 10 & 2.28 & 1.73 & 0.55 \\
\hline 500 & 107.99 & 80.64 & 27.35 \\
\hline 1000 & 215.8 & 161.1 & 54.7 \\
\hline 5000 & 1078.22 & 804.77 & 237.45 \\
\hline 10.000 & 2156.25 & 1609.36 & 546.89 \\
\hline 50.000 & 10780.46 & 8046.08 & 2734.38 \\
\hline 100.000 & 21560.74 & 16091.98 & 5468.76 \\
\hline 145.537 & 31456.31 & 23444.61 & 8011.7 \\
\hline 145.538 & Not Detected & 23444.78 & - \\
\hline
\end{tabular}

\section{Ujicoba Perbandingan Waktu Parsing Data}

Dari hasil uji coba proses parsing data dengan format data XML dan JSON diatas bertujuan untuk membandingkan format data mana yang memiliki waktu paling kecil antara proses parsing data XML dan JSON. Hasil perbandingan parsing data XML dan JSON ditunjukan pada Tabel 3.

Tabel 3. Hasil Ujicoba Waktu Parsing Data Di Jaringan Localhost

\begin{tabular}{|c|c|c|c|}
\hline Jumlah_Record & $\begin{array}{c}\text { Waktu Parsing } \\
\text { data XML (ms) }\end{array}$ & $\begin{array}{c}\text { Waktu Parsing } \\
\text { data JSON (ms) }\end{array}$ & Selisih \\
\hline 10 & 0.127 & 0.092 & 0.035 \\
\hline 500 & 0.151 & 0.111 & 0.04 \\
\hline 1000 & 0.213 & 0.15 & 0.063 \\
\hline 5000 & 0.703 & 0.43 & 0.273 \\
\hline 10.000 & 1.293 & 0.998 & 0.295 \\
\hline 50.000 & 11.373 & 6.244 & 5.129 \\
\hline 100.000 & 28.96 & 22.749 & 6.211 \\
\hline 145.537 & 86.312 & 41.623 & 44.689 \\
\hline 145.538 & Not Detected & 87.611 & - \\
\hline
\end{tabular}

\section{Uji Coba Jaringan Internet}

Pada uji coba jaringan internet, proses serialisasi data dilakukan pada service provider dan selanjutnya service consumer melakukan proses parsing data pada jaringan internet. Dari hasil uji coba proses parsing data dengan format data XML dan JSON diatas bertujuan untuk membandingkan format data mana yang memiliki waktu paling kecil antara proses parsing data XML dan JSON. Hasil perbandingan parsing data XML dan JSON ditunjukan pada Tabel 4. 
Tabel 4. Ujicoba Waktu Parsing Data Di Jaringan Internet

\begin{tabular}{|c|c|c|c|c|c|}
\hline \multirow{2}{*}{$\begin{array}{l}\text { Jumlah } \\
\text { Record }\end{array}$} & \multirow{2}{*}{$\begin{array}{c}\text { Waktu } \\
\text { Parsing data } \\
\text { XML (ms) }\end{array}$} & \multirow{2}{*}{$\begin{array}{c}\text { Waktu } \\
\text { Parsing data } \\
\text { JSON (ms) }\end{array}$} & \multirow{2}{*}{$\begin{array}{c}\text { Selisih } \\
\text { (ms) }\end{array}$} & \multicolumn{2}{|c|}{ Kecepatan Modem } \\
\hline & & & & $\begin{array}{l}\text { Ūpload } \\
\text { (Ḱb/s) }\end{array}$ & $\begin{array}{c}\text { Download } \\
(\mathrm{Kb} / \mathrm{s})\end{array}$ \\
\hline 10 & 0.148 & 0.17 & -0.022 & 0.09 & 1.38 \\
\hline 500 & 1.68 & 1.755 & -0.075 & 0.50 & 17.39 \\
\hline 1000 & 5.09 & 5.014 & 0.076 & 0.32 & 22.94 \\
\hline 5000 & 27.335 & 21.541 & 5.794 & 0.60 & 22.91 \\
\hline 10.000 & 68.462 & 55.756 & 12.706 & 0.21 & 15.615 \\
\hline 50.000 & Not Detected & Not Detected & - & 0.41 & 30.11 \\
\hline 100.000 & Not Detected & Not Detected & - & 0.29 & 26.43 \\
\hline 145.537 & Not Detected & Not Detected & - & 0.25 & 29.98 \\
\hline 145.538 & Not Detected & Not Detected & - & 0.34 & 24.12 \\
\hline
\end{tabular}

\section{Analisa Hasil Ujicoba}

\section{Analisa Waktu Serialisasi Data XML Dan JSON}

Analisa dilakukan pada proses perhitungan waktu serialisasi data XML dan JSON di jaringan localhost untuk mengetahui selisih perbedaan waktu serialisasi data antara XML dan JSON. Grafik selisih waktu serialisasi data dan dapat dilihat pada Gambar 4.

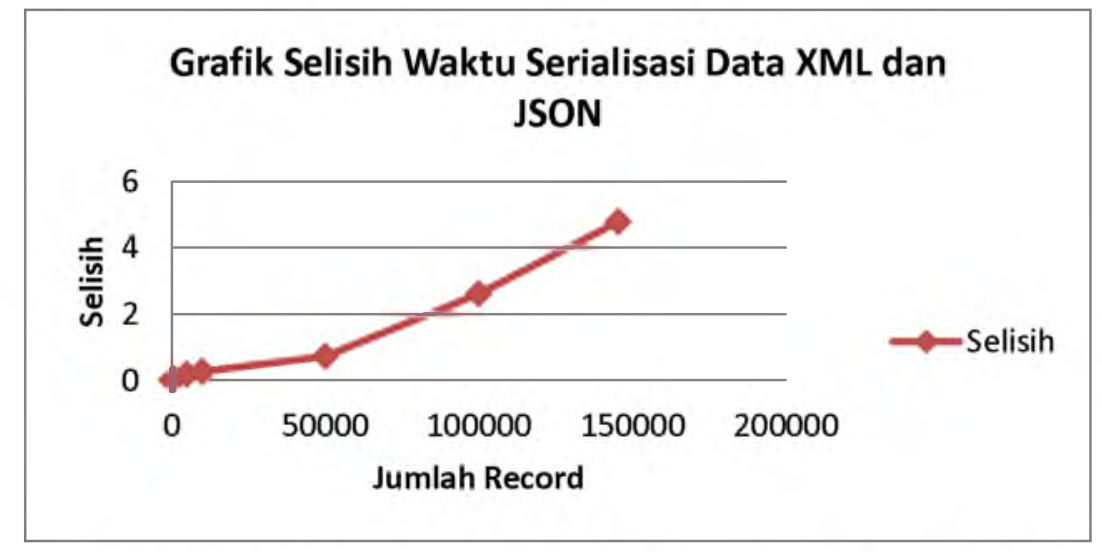

Gambar 4. Grafik Selisih Waktu Serialisasi Data di Jaringan Localhost

\section{Analisa Pengukuran Data XML dan JSON}

Analisa dilakukan pada proses perhitungan ukuran data XML dan JSON di jaringan localhost untuk mengetahui selisih perbedaan ukuran data antara XML dan JSON. Grafik selisih ukuran data XML dan JSON dan dapat dilihat pada Gambar 5. 




Gambar 5. Grafik Selisih Ukuran Data di Jaringan Localhost

\section{Analisa Proses Parsing Data}

Analisa dilakukan pada proses perhitungan waktu parsing data XML dan JSON di jaringan localhost dan internet untuk mengetahui selisih perbedaan waktu parsing data antara XML dan JSON. Grafik selisih waktu parsing data di jaringan localhost dapat dilihat pada Gambar 6 dan grafik selisih waktu parsing data di jaringan internet dapat dilihat pada Gambar 7.

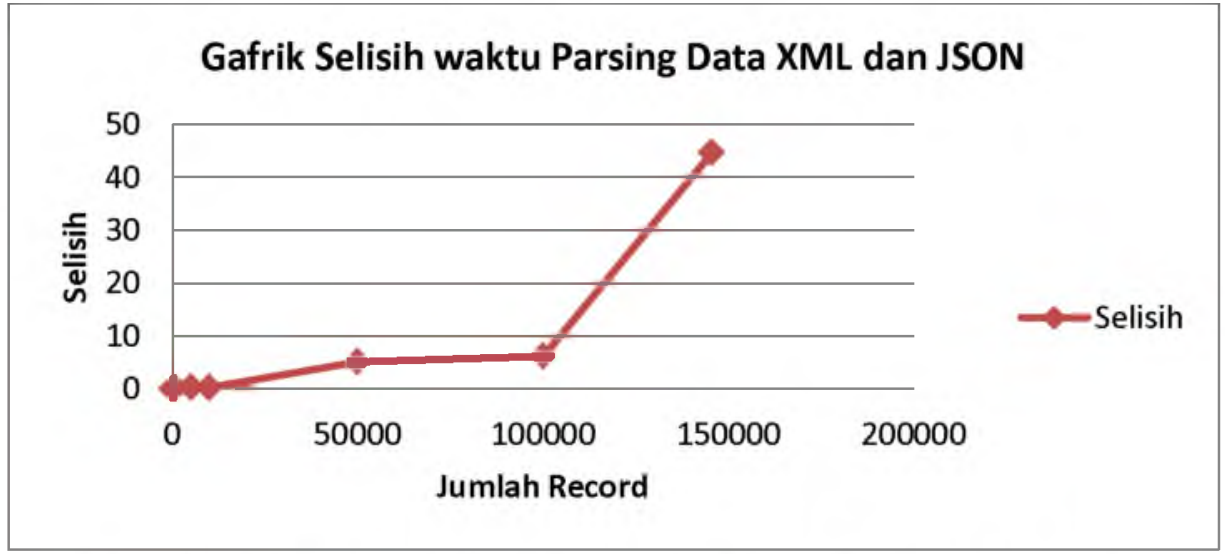

Gambar 6. Grafik Selisih Waktu Parsing Data di Jaringan Localhost

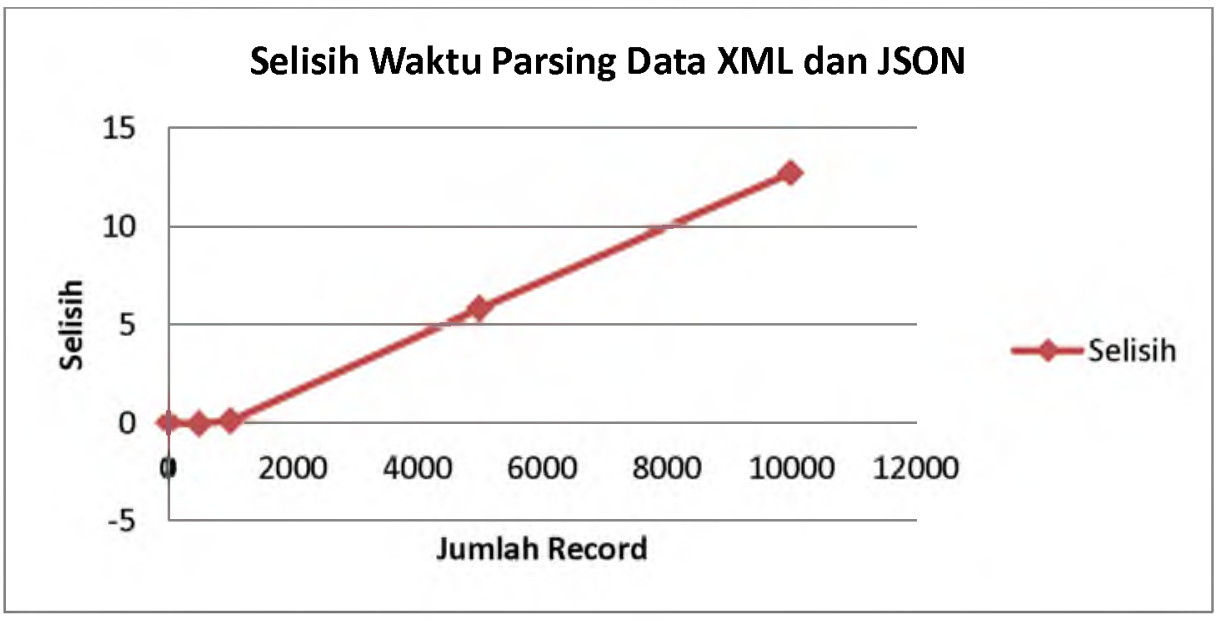

Gambar 7. Grafik Selisih Waktu Parsing Data di Jaringan Internet 


\section{Analisa Hasil Pengujian Keseluruhan}

Pada penelitian ini berdasarkan hasil pengujian dari ujicoba perhitungan waktu serialisasi data, ujicoba perhitungan ukuran data, ujicoba waktu parsing data yang di lakukan pada jaringan localhost dan jaringan internet menggunakan webservice REST menunjukan bahwa selisih waktu dipengaruhi oleh jumlah record data, jika jumlah record semakin banyak maka selisihpun semakin besar sehingga dapat disimpulkan bahwa JSON lebih cepat pada proses serialisasi data dan proses parsing data daripada XML dan memiliki ukuran data lebih kecil dibandingkan XML.

\section{Kesimpulan Dan Saran}

\section{Kesimpulan}

Dari hasil analisa perbandingan XML dan JSON pada aplikasi platform PHP dengan arsitektur REST disimpulkan sebagai berikut:

1. Dari hasil pengujian selisih waktu serialisasi dan waktu parsing data XML dan JSON di pengaruhi oleh jumlah record, jika jumlah record semakin besar makan selisih waktu serialisasi data dan waktu parsing data semakin besar juga hal ini dapat disimpulkan bahwa JSON lebih cepat pada proses serialisasi dan parsing data dibandingkan XML.

2. Dari hasil Pengujian Ukuran data JSON lebih kecil dari pada Ukuran XML.

3. Pertukaran data dengan menggunakan format XML memiliki batas limit size sampai 31456.31 KB sedangkan JSON melebihi batas limit size XML.

4. Hasil Pengujian pada jaringan internet ketika jumlah record mencapai 50.000 data waktu serialisasi data dan waktu parsing data tidak dapat terditeksi pada database.

\section{Saran}

Adapun saran yang diberikan untuk pengembangan penelitian ini adalah sebagai berikut:

1. Dalam pengembangan kedepan terhadap metode pengujian perbandingan format data XML dan JSON dapat menggunakan konsep Relational XML untuk pengujian dengan kapasitas data yang sangat besar.

2. Setelah menggunakan konsep Relational XML data dapat dibagi menjadi beberapa bagian data untuk pengujian selanjutnya.

\section{Daftar Pustaka}

Riyanto, 2011, Sistem Penjualan Berbasis Web dengan PHP dan PostgreSQL, GAVA MEDIA Yogyakarta.

Simpson, J. E., 2002, Just XML, Andi Offset. Yogyakarta.

Siregar, I. M., 2012, Membongkar Teknologi Web Service Jilid 2, Andi Offset. Yogyakarta.

Didiek S. Wiyono, Ardhi Wijayanto, 2012, Implementasi Rest Web Service Dengan Menggunakan Ison Pada Aplikasi Mobile Enterprise Resource Planning.pdf,

http://issuu.com/indraaa/docs/09_v11_n2_p143_152_didiek, diakses pada tanggal 15 Mei 2013.

Nurzhan Nurseitov, Michael Paulson, Randall Reynolds, dan Clemente Izurieta, 2009, Studi Kasus Perbandingan Format Pertukaran Data Pada JSON dan XML.pdf, http://www.cs.montana.edu/izurieta/pubs/caine2009.pdf, diakses pada tanggal 15 Mei 2013. 
Yanuar Firdaus Arie Wibowo, Dana Sulistiyo Kusumo, Annas Abdillah Marta, 2008, Seminar Nasional UPN Veteran Yogyakarta ISSN 1979-2329, Optimasi Perfomansi Ajax Dengan Menggnakan JSON.pdf,

http://repository.upnyk.ac.id/93/1/8 Optimasi Performansi AIAX Dengan Menggunakan ISO $\underline{N \text { i.pdf }}$, diakses pada tanggal 18 Mei 2013.

JSON. json.org. http://wwww.json.org diakses pada tanggal 15 Mei 2013.

Extensible Markup Language (XML), http:/hwww.w3.org/XML/, diakses pada tanggal 15 Mei 2013.

XML http://wwww.xml.com/pub/a/98/10/guide0.html?page=2\#AEN63 diakses pada tanggal 15 Mei 2013

Web Services Architecture, http://wwww.w3.org/TR/ws-arch/diakses pada tanggal 15 Mei 2013. 
Saryanto, Sumarsono, Nurcahyani Dewi Retrowati 